\title{
Seven Cases of Jaundice in Women Taking an Oral Contraceptive, Anovlar
}

\author{
K. E. THULIN,* M.D. ; JERKER NERMARK,† M.B.
}

There have been several reports recently of the possibility of liver damage following the use of oral-contraceptive pills. Cullberg et al. (1965) made a survey of 16 reports of investigations of liver function in patients on oral contraceptives. These reports included general clinical trials and solitary cases of jaundice published during the last three years. The reports were in part contradictory but it was possible to distinguish certain common features. In several large-scale long-term investigations of women in the reproductive years taking contraceptive pills serum-transaminase levels were found to be normal, with only solitary exceptions in some of the series. However, in two studies pathological bromsulphalein (B.S.P.) retention occurred in $4-20 \%$ of cases, while a number of smaller studies of menopausal women showed increase of transaminase values up to $100 \%$ and also ocassional elevation of the serum bilirubin. But a recent report from Bakke (1965), who had treated 36 menopausal women with mestranol ${ }^{1}$ or Enavid, ${ }^{2}$ gave no evidence of significant changes in the liver-function tests.

Stoll et al. (1965) administered Lyndiol $^{3}$ at six times the normal dosage to four menopausal women and reported two cases of jaundice, and elevated bilirubin values in the others. Liver biopsy showed centrilobar parenchymal-cell necrosis in all four cases and cholestasis in the two with jaundice. In addition, three recent reports have been published in which a total of about 400 young women had been treated with various oral-contraceptive pills. Two of these studies (Larsson-Cohn, 1965, and Eisalo et al., 1965) reported slightly increased transaminase values in $4-18 \%$ and increased B.S.P. retention in $19-48 \%$, but also elevated values of thymol turbidity in 3-11\%. Swyer and Little (1965) found one case of increased bilirubin value in twelve women who had taken oral-contraceptive pills continuously for three to six years, but no other abnormal values in liver-function tests. Solitary cases of clinical jaundice in young women taking oralcontraceptive pills have also been reported by Adlercreutz (1964), Ikonen (1964), Sotaniemi et al. (1964) and Cullberg et al. (above).

\section{Material}

During a period of two months (December 1964 and January 1965) six women with clinical jaundice were admitted to the Department of Infectious Diseases, University Hospital, Lund, all of whom had been taking Anovlar ${ }^{4}$ for periods of time ranging from twenty days to six months. Four cases were under treatment for dysmenorrhoea or endometriosis; the other two had used Anovlar for contraceptive purpose only. The dosage was in all cases one tablet a day.

\section{Case Reports}

Case 1.-A gravida-0 aged 37 had complained of premenstrual tension and dysmenorrhoea, which often kept her in bed on the first day of menstruation. She had been under gynaecological observation for one year with suspected endometriosis in the pouch of Douglas.

Case 2.-A gravida-2 aged 29 gave a history of urticaria in childhood and a tendency for allergic eczema. One month before admission she had been operated on for pelvic endometriosis.
Case 3.-A gravida-0 aged 21 had suffered from severe dysmenorrhoea since puberty. In 1961 she had an illness with tonsillitis and painful joints.

Case 4.-A gravida-0 aged 19 complained of premenstrual tension and dysmenorrhoea. She gave a history of developing an allergic exanthematous rash after eating apples.

Case 5.-A gravida-3 aged 32 gave a history of eclampsia in 1953 and pre-eclampsia in 1963. At 16 she had had an illness described as "rheumatic fever and chorea." Since then she had been subject to recurrent painful swelling of the joints of the hands. She developed gall-bladder dyspepsia after eating eggs.

Case 6.-A gravida-2 aged 34 gave a history of premature delivery at the 33rd and 34th week respectively in 1949 and 1951 . Jaundice had developed four days before her last delivery (incompatible Rh-group). Severe itching had occurred late in both pregnancies.

\section{Investigation}

All women were jaundiced on admission and afebrile with no other abnormal physical signs. No drug suspected of producing jaundice had been taken at the same time as the Anovlar medication in any of these cases. The patients gave no history of jaundice, and denied exposure to hepatitis. There was no explanation of the fact that so many cases of clinical jaundice associated with the use of oral contraceptives were collected in such a short period at one clinic. At the Department of Gynaecology, Lund, Anovlar was prescribed for about 500 women in 1964, and a number of private practitioners within the area also prescribed the drug.

The laboratory findings of interest are shown in Table $I$. Elevated bilirubin values and significantly raised transaminase levels were found in all six cases, but the thymol turbidity values were normal and in five of the six cases the alkaline phosphatase values were practically normal. Lactatedehydrogenase values were normal. These results pointed to liver dysfunction in an acute stage, and differed from those in drug-induced jaundice in that the alkaline phosphatase level was not raised.

Electrophoresis of the plasma proteins was performed in four cases. The tests were carried out in the week following the onset of jaundice; all showed a similar distribution of the protein fractions with clear elevation of $\alpha_{2}$ - and $\beta$-fractions. The $\gamma$-globulin fractions were within normal limits in three cases, but in Case 4 there was a slight increase. This pattern is similar to that seen in obstructive jaundice; normal $\gamma$-globulin values usually exclude infectious hepatitis or cirrhosis.

\section{Liver Biopsy}

Liver biopsy with a Vim-Silvermann needle was performed in the department of gynaecology. All six

* Head of the Department of Infectious Diseases, University Hospital, Lund.

† Now Senior Medical Officer of Health, Lund.

Mestranol.-1 pill contains : 0.15 mg. mestranol (3 methoxy-17ethinyloestradiol).

${ }^{2}$ Enavid.-1 pill contains : mestranol $0.075 \mathrm{mg}$. + norethynodrel $5 \mathrm{mg}$.

3 Lyndiol-1 pill contains: mestranol $0.15 \mathrm{mg}$ + + lynoestrenol $5 \mathrm{mg}$

- Ancvlar.-1 pill contains : ethinyloestradiol $0.05 \mathrm{mg}$. + norethisterone acetate $4 \mathrm{mg}$. 
TABLE I.-Laboratory Investigations

\begin{tabular}{|c|c|c|c|c|c|c|c|c|c|c|c|c|}
\hline \multicolumn{13}{|c|}{ (20) } \\
\hline & \multicolumn{2}{|c|}{1} & \multicolumn{2}{|c|}{2} & \multicolumn{2}{|c|}{3} & \multicolumn{2}{|c|}{4} & \multicolumn{2}{|c|}{5} & \multicolumn{2}{|c|}{6} \\
\hline & A & B & A & B & A & B & A & B & A & B & A & B \\
\hline 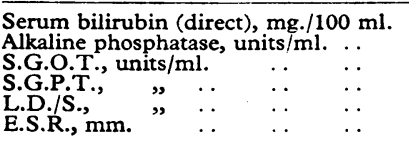 & $\begin{array}{r}6 \cdot 7 \\
6 \\
450 \\
845 \\
270 \\
31\end{array}$ & $\begin{array}{l}3 \cdot 0 \\
6 \\
145 \\
365 \\
250 \\
26\end{array}$ & $\begin{array}{r}7 \cdot 2 \\
7 \\
355 \\
695 \\
340 \\
6\end{array}$ & $\begin{array}{c}4 \cdot 4 \\
10 \\
55 \\
160 \\
200 \\
7\end{array}$ & $\begin{array}{r}3 \cdot 0 \\
8 \\
79 \\
225 \\
200 \\
10\end{array}$ & $\begin{array}{r}3 \cdot 4 \\
7 \\
120 \\
245 \\
150 \\
10\end{array}$ & $\begin{array}{l}7 \cdot 2 \\
15 \\
70 \\
85 \\
380 \\
28\end{array}$ & $\begin{array}{r}4 \cdot 5 \\
13 \\
110 \\
115 \\
320 \\
37\end{array}$ & $\begin{array}{r}3 \cdot 3 \\
9 \\
1,100 \\
1,600 \\
37\end{array}$ & $\begin{array}{r}4 \cdot 7 \\
7 \\
125 \\
400 \\
390 \\
10\end{array}$ & $\begin{array}{l}3 \cdot 1 \\
6 \\
56 \\
207 \\
270 \\
21\end{array}$ & $\begin{array}{r}8 \cdot 1 \\
8 \\
40 \\
45 \\
260\end{array}$ \\
\hline
\end{tabular}

A.-Laboratory tests on admission. B. -1-2 weeks later. The upper limits of normal for our laboratory are-Sertm bilirubin $1.2 \mathrm{mg}$./1C0 $\mathrm{ml}$. Serum glutamic pyruvic transaminase (S.G.P.T.) and serum glutamic oxalo-acetic-acid transaminase

cases showed a similar picture, with intrahepatic stasis, a great number of bile thrombi, scanty inflammatory cells, and insignificant to moderate liver cell damage. These patterns correspond to those seen after drug-induced jaundice, most like the mixed hepatocanalicular type described by Zimmerman (1963).

\section{Oral-contraceptive-drug Jaundice and Late-pregnancy Jaundice}

The striking similarity between the jaundice following the use of oral contraceptives and the jaundice in late pregnancy has been pointed out by several authors. Adlercreutz (1964) and Ikonen (1964) each described cases of fertile women who gave histories of late icterus or pruritus gravidarum and who developed jaundice after contraceptive therapy. Case 6 in the present study had severe itching late in both pregnancies and also jaundice in the later one. An additional recent case reported to us from the Department of Medicine at Lund will be described here :

Case 7.-A gravida-3 aged 32 gave a history of pronounced itching late in her first pregnancy and of icterus gravidarum and prolonged post-partum bleeding in 1963. She underwent cholecystectomy in 1950 . The patient had noticed jaundice after more than six months of Anovlar therapy and later developed pain under her right costal margin. Laboratory findings: serum bilirubin $7.1 \mathrm{mg} . / 100 \mathrm{ml}$, serum glutamic pyruvic transaminase (S.G.P.T.) 445 i.u., thymol turbidity and alkaline phosphatase normal. A few days later the values had decreased to $5 \mathrm{mg} . / 100 \mathrm{ml}$. and 273 i.u. respectively in spite of continued Anovlar therapy. A few days after stopping the drug the serum bilirubin had returned almost to normal. Exploratory laparotomy was performed; nothing remarkable was found. The patient restarted her Anovlar medication six weeks later, and on examination at the department of medicine after a further three weeks she was found to have an S.G.P.T. level of 700 i.u., and a serum bilirubin $2.8 \mathrm{mg} . / 100 \mathrm{ml}$. When Anovlar medication was stopped the values very soon returned to normal. No biopsy was performed.

\section{Possible Predisposing Factors}

Adlercreutz (1964) found some features in the past history that might have been relevant in two cases of oralcontraceptive-drug jaundice-irregular menstruation, migraine,

\begin{tabular}{|c|c|c|c|c|c|c|c|c|}
\hline & $\begin{array}{c}\text { Case } \\
1\end{array}$ & $\begin{array}{c}\text { Case } \\
2\end{array}$ & $\underset{3}{\text { Case }}$ & $\underset{4}{\text { Case }}$ & $\underset{5}{\text { Case }}$ & $\underset{6}{\text { Case }}$ & $\begin{array}{c}\text { Case } \\
7\end{array}$ & $\begin{array}{l}\text { No. of } \\
\text { Cases }\end{array}$ \\
\hline $\begin{array}{l}\text { Dysmenorrhoea } \\
\text { Endometriosis }\end{array}$ & $\begin{array}{l}+* \\
+ \\
+ \\
+\end{array}$ & $\begin{array}{l}\overline{+} \\
\overline{-}\end{array}$ & $\begin{array}{l} \pm^{*} \\
= \\
-\end{array}$ & $\begin{array}{l}+* \\
+\end{array}$ & $\bar{z}$ & $\begin{array}{c}- \\
\overline{-} \\
-\end{array}$ & $\begin{array}{l}- \\
\overline{-} \\
-\end{array}$ & $\begin{array}{r}3 \\
2 \\
(1) \\
3\end{array}$ \\
\hline $\begin{array}{l}\text { Number of pregnancies } \\
\text { Pregnancy complica- } \\
\text { tions } \\
\text { Pruritus gravidarum } \\
\text { Icterus gravidarum } \ddagger \\
\text { Gall-tract trouble } \\
\text { Allergic reactions } \\
\text { Rheumatic diseases }\end{array}$ & $\begin{array}{l} \pm \\
-\end{array}$ & $\begin{array}{l}2 \\
= \\
= \\
\pm \\
-\end{array}$ & $\overline{(+)}$ & $\frac{+}{+}$ & $\begin{array}{l}3 \\
2+ \\
= \\
\pm \\
=\end{array}$ & $\begin{array}{l}2 \\
1 \\
2 \\
1 \\
= \\
=\end{array}$ & $\begin{array}{l}3 \\
- \\
1 \\
1 \\
+ \\
-\end{array}$ & $\begin{array}{c}10 \\
3 / 10 \\
3 / 10 \\
2 / 10 \\
3 \\
2 \\
1(2)\end{array}$ \\
\hline
\end{tabular}

* Indication for treatment. + Eclampsia a
dysfunction is anamnestically to be found.
" premenstrual tension," biliary-tract symptoms, and in one of the cases allergy to sulphonamide, and rheumatic fever. Because of this our seven patients were all asked about these symptoms and the results are shown in Table II.

\section{Discussion}

Several papers have been published on the subject of abnormal liver-function tests in menopausal women taking contraceptive pills. There are also reports of abnormal liverfunction tests in young women taking these drugs, but mostly with only slightly increased values. Some isolated cases of jaundice in young women have also been reported.

The present study shows seven clinical cases of jaundice with pathological liver-function tests in young women taking Anovlar. It is highly probable that the jaundice was the result of the treatment with this drug.

The biopsy findings showed the picture of intrahepatic stasis with slight hepatocellular damage, as with drug-induced jaundice of chlorpromazine type. The clinical laboratory tests, however, differed from the pattern that is considered characteristic of chlorpromazine damage-that is, highly raised alkaline phosphatase values and transaminase levels not exceeding 300 i.u.

In these seven patients we found rormal or only slightly increased alkaline phosphatase values and in four cases the S.G.P.T. exceeded 400 i.u. This divergence with jaundice of chlorpromazine type in relation to laboratory findings is of interest in the differential diagnosis of jaundice, and may be indicative of another type of liver damage.

One object of our study has been the investigation of the possibility of there being predisposing factors in the development of oral-contraceptive-drug jaundice. As the number of cases is small and of a partly selected nature, the conclusions must naturally be tentative. Two cases with icterus gravidarum and one case with severe pruritus gravidarum (Adlercreutz, Ikonen), who developed oral-contraceptive-drug jaundice are quoted above. As two more cases are mentioned in the present series a history of icterus or pruritus gravidarum must be considered a contraindication for treatment with contraceptive tablets. The prognosis has been good in the solitary cases published so far. Of the present cases all recovered with almost normal liver-function tests within one to two months of the onset of jaundice. All suffered, however, from prolonged tiredness and inability to work, and, moreover, two of the patients had severe pruritus. As the diagnosis was uncertain one of the patients underwent cholecystectomy.

As this type of jaundice still seems to be overlooked it is probable that a number of patients with jaundice of unknown aetiology have in fact been suffering from oral-contraceptivedrug jaundice.

\section{Summary}

Seven cases of clinical jaundice after treatment with contraceptive pills (Anovlar) are described. Liver biopsy was 
performed in six of the cases with histological changes very similar to those seen in chlorpromazine-induced jaundice. The laboratory findings were a normal or only slightly raised alkaline phosphatase value and high transaminase levels. Certain features in the history were present in several cases: two had suffered from icterus and pruritus gravidarum, and this should be regarded as a contraindication to the use of contraceptive pills. The widespread use of oral contraceptives leads us to the supposition that this cause for jaundice is sometimes overlooked.
REFERENCES

Adlercreutz, H. (1964). Nord. med., 72, 1004

Bakke, J. L. (1965). Brit. med. F., 1, 631.

Cullberg, G. Lundström Re. and Stenram, U. (1965). Ibid. $1,695$.

Eisalo, A., Järvinen, P. A., and Luukkainen, T. (1964). Ibid., 2, 426 Eisalo, A., Jarvinen, ${ }^{2}$. A., and Luukkaine

Ikonen, E. (1964). Acta obstet. gynec. scand., 43, Suppl. No. 5.

Larsson-Cohn, U. (1965). Brit. med. Y., 1, 1414.

Sotaniemi, E., Kreus, K. E., and Scheinin, T. M. (1964). Ibid., 2, 1264.

Stoll, B. A., Andrews, J. T., Motteram, R., and Upfill, J. (1965). Ibid., 1, 723 .

Swyer, G. I. M., and Little, V. (1965). Ibid., 1, 1412.

Zimmerman, H. J. (1963). Ann. N.Y. Acad. Sci., 104, 954.

\title{
Thirst Fever, with a Characteristic Temperature Pattern in Infants in Kuwait
}

\author{
YEHIA SHAKER,* M.D., D.C.H
}

Brit. med. F., 1966, 1, 586-588

The importance of water metabolism in infancy and childhood is well recognized. The high metabolic rate of infants as compared with that of adults, the relative excess of their bodywater with a greater daily turnover, as well as the immaturity of their renal function, explain the increased need for water In this age-group and the marked intolerance to water-deprivation. A slight change in the fluid intake, though negligible In an adult, may be serious in a little child with a small total fluid volume and a fairly narrow limit of variability (Hill, 1954).

Fever due to water-deprivation is well known in the newborn. In older infants it is rather rare but sometimes creates diagnostic problems. It may, however, occur in hot climates. In Greece, Choremis et al. (1959) described cases in which infants had an irregular prolonged fever as the only symptom

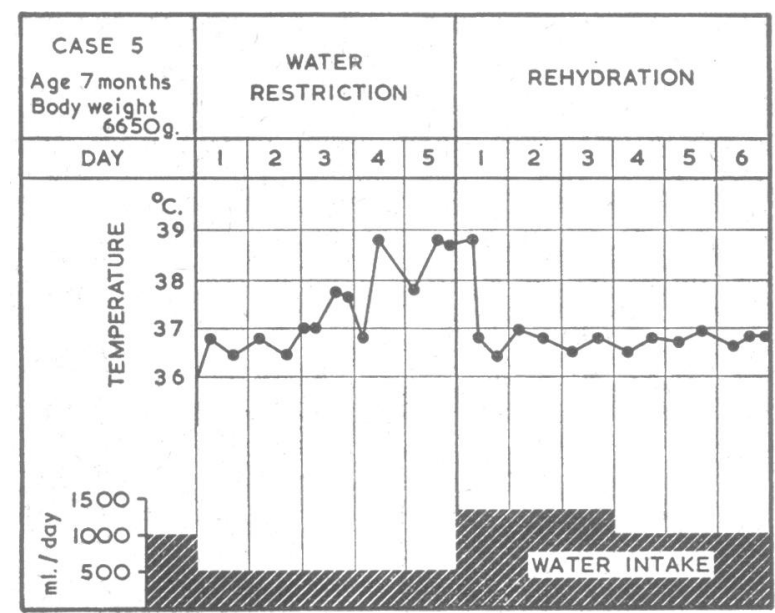

FIG. 1.-Experimentally induced thirst fever and its correction by rehydration (after Choremis et al., 1959). Reproduced by permission, from Helvetica paediatrica acta.

of inadequate water intake, occurring particularly during summer. They also produced such a fever experimentally in infants (Fig. 1).

Thirst fever is due to a relative or an absolute lack of water, resulting in an inadequate reduction of heat. It can therefore occur when the water intake is not sufficient for the needs of

* From the Paediatric Department, Al Sabah Hospital, Kuwait. the infant or when its food is too rich in calories or in proteins and it is not getting any extra water. Holliday and Segar (1957) have estimated that for every gramme of protein given in excess of the minimum requirement $20 \mathrm{ml}$. of extra water is needed to excrete the products of protein catabolism in a larger volume of urine. Increased salt intake has also been described as a cause of fever (Finkelstein, 1938 ; Levesque and Bastin, 1949).

The diagnosis of fever due to water-deprivation is not always easy. It should be based on a careful history, the lack of any other abnormal clinical or laboratory findings, the failure of the infant to respond to any kind of drug treatment, and finally the subsidence of the fever after administration of extra water alone.

This paper presents a clinical variety of thirst fever with a characteristic temperature pattern.

\section{Material and Results}

During the past few years some cases have been referred to the paediatric consultation clinic because of a prolonged pyrexia of unknown origin, most of the patients having already received various kinds of medical treatment without improvement.

Seventeen such patients (10 males and 7 females) were studied (see Table). Fifteen were followed up as out-patients; the other two were admitted to hospital. Their ages ranged from 3 to 10 months with one exception, a male infant aged 13 months. Only one infant was a Kuwaiti ; the rest were of other nationalities. All the cases presented during the hot humid season. The main presenting feature was a pyrexia of long duration, varying between 12 and 68 days. All the infants except one showed a similar unusual pattern of fever-high (ranging from 39 to $40.8^{\circ} \mathrm{C}$. per rectum) in the morning and gradually falling during the day, to become normal or almost normal in the evening (Fig. 2).

Apart from the fever, no significant abnormal findings could be detected on clinical examination. Three cases, however, showed early rickets, manifested by craniotabes and/or increased head-sweating (see Table). All the infants were active well-fed babies of average normal weight for their age. Their appetite was good. Only two patients (Cases 6 and 17) were exclusively breast-fed ; the rest were having either artificial or mixed feeding, with or without some solid food. The exact 